\title{
An Integrated Approach to Monitoring a Field Test of In Situ Contaminant Destruction
}

\author{
Robin L. Newmark, Roger D. Aines, G. Bryant Hudson, Roald Leif, \\ Marina Chiarappa, Charles Carrigan, Allen Elsholtz, LLNL \\ Craig Eaker, Southern California Edison Company, Rosemead, CA
}

This paper was prepared for submittal to the

Symposium on the Application of Geophysics to Engineering and Environmental Problems

Oakland, California

March 14-18, 1999

December 1998

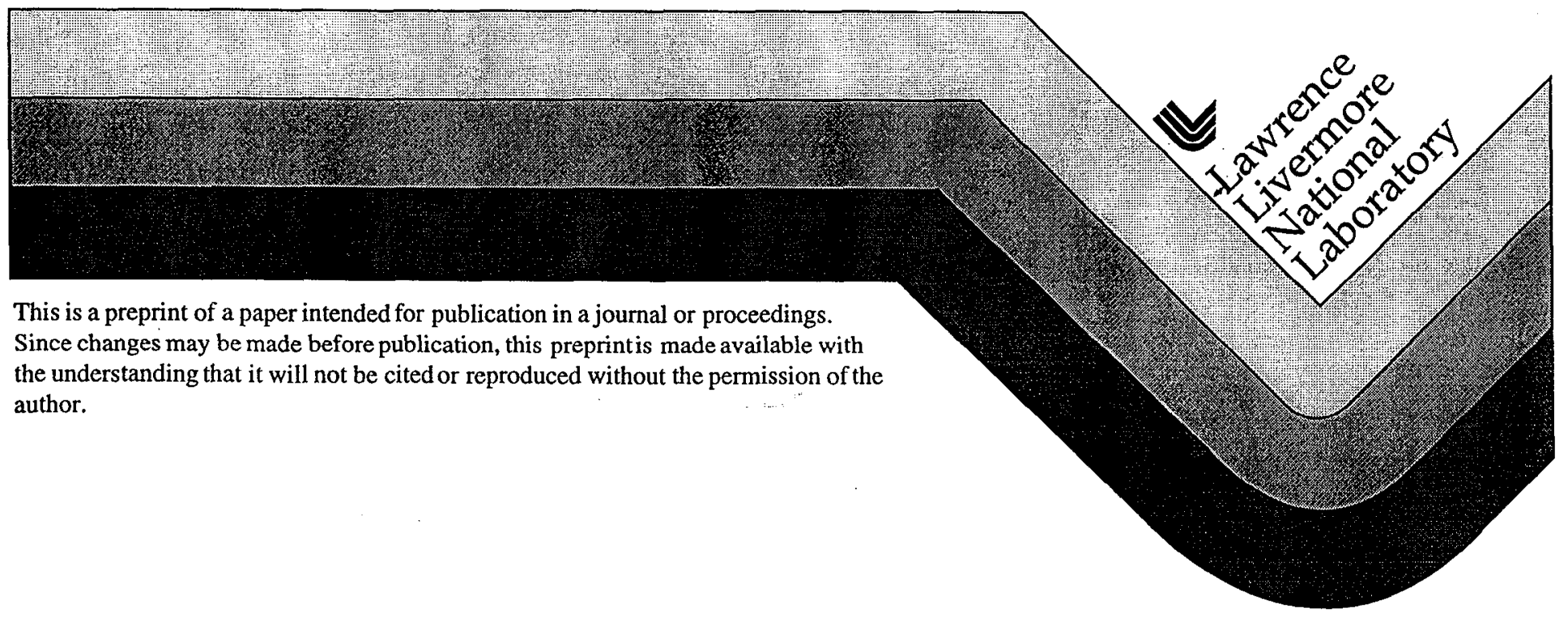




\section{DISCLAIMER}

This document was prepared as an account of work sponsored by an agency of the United States Government. Neither the United States Government nor the University of California nor any of their employees, makes any warranty, express or implied, or assumes any legal liability or responsibility for the accuracy, completeness, or usefulness of any information, apparatus, product, or process disclosed, or represents that its use would not infringe privately owned rights. Reference herein to any specific commercial product, process, or service by trade name, trademark, manufacturer, or otherwise, does not necessarily constitute or imply its endorsement, recommendation, or favoring by the United States Government or the University of California. The views and opinions of authors expressed herein do not necessarily state or reflect those of the United States Government or the University of California, and shall not be used for advertising or product endorsement purposes. 


\title{
AN INTEGRATED APPROACH TO MONITORING A FIELD TEST OF IN SITU CONTAMINANT DESTRUCTION
}

\author{
Robin L. Newmark ${ }^{1}$, Roger D. Aines ${ }^{1}$, G. Bryant Hudson ${ }^{1}$, Roald Leif ${ }^{1}$, \\ Marina Chiarappa ${ }^{1}$, Charles Carrigan ${ }^{1}$, Allen Elsholz, ${ }^{1}$, ${ }^{1}$ ig Eaker ${ }^{2}$ \\ ${ }^{1}$ Lawrence Livermore National Laboratory, Livermore, CA, 94550, USA \\ ${ }^{2}$ Southern California Edison Company, Rosemead, CA., 91770, USA
}

\begin{abstract}
The development of in situ thermal remediation techniques requires parallel development of techniques capable of monitoring the physical and chemical changes for purposes of process control. Recent research indicates that many common contaminants can be destroyed in situ by hydrous pyrolysis/oxidation (HPO), eliminating the need for costly surface treatment and disposal. Steam injection, combined with supplemental air, can create the conditions in which HPO occurs. Field testing of this process, conducted in the summer of 1997, indicates rapid destruction of polycyclic aromatic hydrocarbons (PAHs). Previous work established a suite of underground geophysical imaging techniques capable of providing sufficient knowledge of the physical changes in the subsurface during thermal treatment at sufficient frequencies to be used to monitor and guide the heating and extraction processes. In this field test, electrical resistance tomography (ERT) and temperature measurements provided the primary information regarding the temporal and spatial distribution of the heated zones.
\end{abstract}

Verifying the in situ chemical destruction posed new challenges. We developed field methods for sampling and analyzing hot water for contaminants, oxygen, intermediates and products of reaction. Since the addition of air or oxygen to the contaminated region is a critical aspect of HPO, noble gas tracers were used to identify fluids from different sources. The combination of physical monitoring with noble gas identification of the native and injected fluids and accurate fluid sampling resulted in an excellent temporal and spatial evaluation of the subsurface processes, from which the amount of in situ destruction occurring in the treated region could be quantified. The experimental field results constrain the destruction rates throughout the site, and enable site management to make accurate estimates of total in situ destruction based on the recovered carbon. As of October, 1998, over $400,000 \mathrm{~kg}(900,000 \mathrm{lb})$ of contaminant have been removed from the site; about $18 \%$ of this has been destroyed in situ.

\section{INTRODUCTION}

A key issue in the application of in situ contaminant destruction methods is the ability to verify the destruction has taken place. Methods involving the injection of fluids into contaminated soils have the innate problem of proving that the resultant contaminant reduction is produced via the method demonstrated, and not merely resulting from either dilution or displacement of contaminated ground water. In a recent field test of combined thermal methods at the Visalia Pole Yard, Visalia, CA, we combined a suite of techniques to monitor the physical changes and progress of chemical destruction in situ. At Visalia, Southern California Edison Co. (Edison) is applying the Dynamic Underground Stripping (DUS) thermal remediation method to clean up a large $(4.3 \mathrm{acre})$ site contaminated with pole-treating compounds. This is a full-scale cleanup, during which extraction of contaminants is augmented by combined steam/air injection in order to enhance the destruction of residual contaminants by hydrous pyrolysis/oxidation (HPO) (Cummings, 1997). The site currently contains DNAPL product composed of pole-treating chemicals (primarily creosote and pentachlorophenol) and an oil-based carrier. The chemicals are 
present in the alluvial soil and ground water from near the surface, through the shallow aquifers (from 11-23 $\mathrm{m}(35-70 \mathrm{ft})$ ), to the base of the intermediate aquifer at $32 \mathrm{~m}(105 \mathrm{ft}$ ) below ground surface (Geraghty and Miller, 1992). The most important ground water resource is found in the deep aquifer, below about $37 \mathrm{~m}(120 \mathrm{ft})$. The thermal remediation system was designed to remove contaminant from the intermediate and shallow aquifers, without disturbing the deep aquifer.

DUS combines soil heating techniques (steam injection and/or electrical heating) and vacuum extraction to heat the soil, mobilize and remove organic contaminants (Newmark et al., 1997, 1998). Laboratory results indicated that hydrous pyrolysis/oxidation can play a significant role in the final removal, or polishing of residual contaminant from the soil (Knauss et al., 1997, 1998a-c, Leif et al., 1997), generally viewed to be the most difficult part of a cleanup. Where ground water is oxygenated (i.e., at the edges of the contaminated area, the up-gradient side in particular), hydrous pyrolysis will occur during the initial steaming of the site. After the majority of the product is removed from the site, this process continues. Oxygen can be added to the injected steam to promote the hydrous pyrolysis reaction after collapse of the steam zone. The injected oxygen dissolves in water held as residual saturation during the steam injection pulse, and can readily diffuse from that water into the rest of the aqueous phase after collapse of the steam zone. Thus, the supplemental oxygen can be readily delivered to the heated "reaction zone". Because of the difficulty of extracting pentachlorophenol by vapor extraction, its destruction by HPO was anticipated to be a significant factor in the final cleanup of the Visalia site.

Previous work (e.g., Newmark et al., 1994, Ramirez et al., 1995) established a suite of underground geophysical imaging techniques capable of providing sufficient knowledge of the physical changes in the subsurface during thermal treatment at sufficient frequencies to be used to monitor and guide the heating and extraction processes. Electrical resistance tomography (ERT) and temperature measurements provided the primary information regarding the temporal and spatial distribution of the heated zones. Verifying the chemical destruction in situ posed new challenges, along with integrating the various field measurements to determine how the process(es) progress in situ. Laboratory evaluation of HPO is readily accomplished in a closed system. However, the field application constitutes an open environment. Native flowing and pumped ground water are free to move through the test area. In addition, vacuum extraction enhances the supply of atmospheric gases through the vadose zone to interact with the ground water. The field tests were designed to track the physical and chemical changes, identify individual fluids, and thus enable us to quantify the oxygen depletion, carbon dioxide $\left(\mathrm{CO}_{2}\right)$ production and contaminant destruction.

\section{FIELD TESTING IN SITU CHEMICAL DESTRUCTION}

In order to evaluate the progress of the HPO chemical destruction in situ, we conducted two field experiments at the Visalia site. In both experiments, steam was injected into well S4, and physical and chemical monitoring was performed at wells MW36 (a plastic monitoring well) and S13 (a steel-cased extraction well), located $24 \mathrm{~m}$ and $28 \mathrm{~m}$ away, respectively (Figure 1). Steam movement was tracked by ERT and by monitoring thermocouples in nearby cone penetrometer-emplaced vertical electrode (ERT) arrays. Fluids were regularly analyzed at MW36 (using the system described below), and occasionally at $\mathrm{S} 13$, whose downhole pump delivered a non-pressurized, high-volume sample. 
HPO is an aqueous-phase reaction, and it is essential to capture the fluid chemistry for evaluation. At elevated temperatures, many of the key constituents are sufficiently volatile that traditional sampling techniques are not suitable. We developed high temperature packer and pump systems capable of delivering a pressurized, isolated fluid stream to the surface, where in-line analysis can be performed (Newmark et al., 1998). In order to measure key chemical constituents, an in-line analytical system was developed for both dissolved oxygen and organic analyses. In this system, a manifold maintains pressures above hydrostatic on the fluid stream until analyses are performed (i.e., for the gas chromatograph, this involved keeping pressure on the sample stream until a fixed volume sample was collected for input to a purge and trap collection sample handling system). An additional challenge posed was to protect the existing plastic monitoring wells from temperature-induced collapse. The packer systems were modified to provide circulating cooling fluids to both protect these wells and to permit sampling during steam injection. These systems have performed successfully to date, both protecting the wells and providing valuable fluid samples.

Since the addition of air or oxygen to the contaminated region is a critical aspect of HPO, noble gas tracers ( $\mathrm{Xe}, \mathrm{Kr}, \mathrm{Ne}$ and $\mathrm{He}$ ) were used to track the movement of the steam (and subsequent condensation to liquid water) and other gases initially present in the steam (Hudson et al., 1998, Newmark et al., 1998). In most experiments in which some additive (such as nutrients or oxidative chemicals) is introduced into the subsurface after which the chemical contamination is observed to decrease, it is difficult to definitively attribute the decrease in contaminant concentration to a particular process. Introducing fluid into the subsurface can dilute and/or displace the native ground water; contaminant destruction cannot be quantified without some means of identifying the fluids present. The tracers are utilized to identify those fluids directly derived from the injectate of interest, as opposed to native fluids or condensate from injection wells elsewhere in the field. They permit us to follow the injected steam/water/oxygen pattern from a single injection well, measuring how well mixing occurs, how oxygen is consumed, $\mathrm{CO}_{2}$ produced/transported and how the intermediate HPO destruction products correlate with temperature and oxygen. Isotopic measurements made on samples of the extracted carbon forms determines the mass of carbon derived from contaminant oxidation as opposed to (modern) atmospheric gas origins. The combination of accurate fluid sampling and tracking of the injected fluids allowed us to determine the amount of in situ destruction occurring in the treated region.

The subsurface conditions are complex, involving multiple phases and phase changes combined with mass and heat transport. Numerical simulations were run using a nonisothermal, unsaturated zone transport code developed at LLNL (NUFT) (Nitao, 1995), which includes individual gas properties in the multi-phase system. These were used as design tools for the field experiments and to aid in interpretation. Model calculations give tracer concentrations in time and space that are directly comparable to measurements. The experimental results showed remarkably close agreement with the simulations (Newmark et al., 1998). The modeling predicted steam and tracer movement to within an hour or two in most instances. Modeling also effectively predicted the time of "thermal breakthrough", which occurs when sufficient heat has built up in the subsurface for vaporization of contaminants to begin, and "steam collapse", which is the opposite phenomenon, reflecting the condensation of the steam zone (Figure 2).

\section{First Experiment: Mixing and Dispersion}

A key question in the design of in situ HPO systems is the degree to which the heat, oxygen and contaminant can be mixed. Strong dispersive mixing of oxygen, contaminant and hot water is a critical aspect in promoting HPO. Initial concerns focused on whether or 
not piston-like flow conditions would dominate, which would reduce the mixing zones crucial to the success of HPO as an in situ remediation technique. The first tracer experiment was designed to address hydrology issues of mixing and dispersion (Figure 1).

About 80,0001 of xenon-tagged water was introduced to injection well S4, screened from $24-30 \mathrm{~m}$. This was followed by neon-tagged steam injection. The tracers were chosen based on their solubilities; high-solubility xenon will mimic the aqueous phase, where lowsolubility neon will mimic the vapor phase. Sampling was conducted in wells MW36 and S13 until the steam front had passed beyond both monitoring wells. Thermocouple measurements made in the S13 extraction well clearly demonstrate the temperature rise as the steam front approaches and passes the monitoring point (Figure 2). Steam injection ceased, and the front was permitted to collapse back to the injection well. The timing of these events can be found in Table 1. Fluid samples were evaluated for the presence of tracers, intermediates of reaction, contaminant concentration, and dissolved oxygen.

Table 1

\begin{tabular}{|l|l|}
\hline Date and Time & Event \\
\hline $\begin{array}{c}\text { First Tracer Experiment: } \\
\text { Mixing and Dispersion }\end{array}$ & \\
\hline & \\
\hline $5 / 19 / 9715: 55$ & \\
\hline $5 / 20 / 9713: 30$ & Xenon tracer injection begun \\
\hline $5 / 21 / 978: 00$ & Xenon tracer injection complete \\
\hline $5 / 23 / 976: 15$ & Steam and Neon injected into Well S4 \\
\hline $5 / 23 / 976: 40$ & Well S13 exceeds 100 ${ }^{\circ} \mathrm{C}$ (steam passes well) \\
\hline & Injection is halted and steam zone collapses \\
\hline Second Tracer Experiment: & \\
\hline Hydrous Pyrolysis / Oxidation & \\
\hline $6 / 17 / 978: 00$ & \\
\hline $6 / 19 / 9713: 33$ & $\begin{array}{l}\text { Steam, Krypton, and Helium tracer injection } \\
\text { begins in Well S4 }\end{array}$ \\
\hline $6 / 20 / 9710: 37$ & Well S13 exceeds $100^{\circ} \mathrm{C}$ (steam passes well) \\
\hline
\end{tabular}

\section{Table 1. Time history of the two tracer experiments.}

Large dispersive mixing of the tracers was observed (Figure 3A). This is in good agreement with calculations when realistic random permeability field realizations are used in the subsurface model. Calculations using uniform media underestimate dispersive mixing by more than a factor of ten, in clear contrast to field measurements. The ratio of tracer gas to natural air mixed into water was much greater than predicted by the model's initial assumption of no mixing of the injected steam and native ground water, showing the process to be more efficient than envisioned and favoring the success of HPO in the field (Figure 4). In short, the results of this first experiment yielded excellent results favoring the success of HPO in the field.

\section{Second Experiment: Hydrous Pyrolysis / Oxidation}

The focus of the second tracer experiment was on HPO. Compressed air was injected along with the steam, in order to enhance HPO. Both helium and krypton were injected 
along with the steam and compressed air; the tracer solubilities mimic the aqueous and vapor phases in a similar manner to the xenon and neon used in the first experiment (Figure 3B). Once again, the gradual increase in tracer concentrations support significant mixing and dispersion. This is accompanied by a decrease in dissolved oxygen, indicating that $\mathrm{HPO}$ is occurring along the leading edge of the steam front.

Evidence of the progress of HPO comes from a number of sources, including the disappearance of dissolved oxygen (consumed through the HPO reactions), the appearance of oxidized intermediates, the production of $\mathrm{CO}_{2}$ (a final product of $\mathrm{HPO}$ ), and the isotopic provenance of the carbon it contains (indicating the destruction of contaminant rather than other carbon sources). In the second experiment, steam injection was supplemented with air injection, increasing the dissolved oxygen available for HPO. Positive evidence of HPO was found on all counts (Newmark et al., 1998). A surprising finding was evidence of HPO occurring during and after the first, hydrology-focused experiment, which did not include the supplemental air (and thus oxygen).

The chemical results are described in detail in Aines et al. (1998) and Leif et al. (1998). Dissolved oxygen decreased in fluids after steam collapse in both experiments, indicating the consumption of oxygen during HPO. Oxidized intermediates were measured in fluid samples within a few days of steam collapse (oxidized intermediate concentrations increased dramatically in the extraction wells when steam injection ceased in the western wells in mid July as well). Carbon dioxide, the final product of the HPO reaction, was measured in the vapor phase present in both the injection well and in S13. This steam-rich vapor consists of a steam- $\mathrm{CO}_{2}$ mixture with small amounts of air. The extraction well also contained large amounts of oxidized intermediate products, consistent with laboratory results.

The combined results from the chemical and isotopic measurements of oxidation at Visalia indicate that hydrous pyrolysis/oxidation of creosote compounds in ground water occurs readily at steam-derived temperatures of 100 to $110^{\circ} \mathrm{C}$. This result is consistent with the observed laboratory rates of degradation. The heated Visalia ground water system is observed to be saturated with both calcium carbonate (calcite) and dissolved air. Newly created inorganic carbon $\left(\mathrm{CO}_{2}\right.$ or bicarbonate) was determined by the change in isotopic composition of the ground water, with measurements of the vadose zone gas and precipitated calcite supporting the ground water analyses. During and directly after injection of steam into an oxygenated subsurface aquifer, ${ }^{14} \mathrm{C}$ and ${ }^{13} \mathrm{C}$ ratios were observed to change by approximately $20 \%$ toward the composition of the hydrocarbon contaminant at the site, implying significant carbon oxidation. This, along with the tracer determination of fluid source composition, requires that active exchange of fresh air was occurring in the aquifer to supply the added oxygen required to oxidize this amount of PAH-carbon (Aines et al., 1998).

\section{RELATIONSHIP TO REMEDIATION RESULTS FOR THE ENTIRE SITE}

The results of the field experiments were applied directly to the overall recovery in the Visalia field. After the initial heating phase (over $380,000 \mathrm{~m}^{3}\left(500,000 \mathrm{yd}^{3}\right)$ at a temperature of $100^{\circ} \mathrm{C}$ or above), Edison adopted a huff and puff mode of operation, where the steam is injected for about a week, then injection ceases for about a week while extraction continues. Maximum contaminant removal is obtained during this steam-off period as the formation fluids flash to steam under the applied vacuum of about $1 / 4$ atmosphere (at $\left.2500 \mathrm{scfm}\left(\sim 1 \mathrm{~m}^{3} / \mathrm{s}\right)\right)$. In September, 1997, Edison began providing supplemental oxygen as compressed air along with steam injection; in situ HPO destruction rates increased from about $140 \mathrm{~kg} /$ day $(300 \mathrm{lb} /$ day) to about $360 \mathrm{~kg} /$ day $(800 \mathrm{lb} /$ day). 
Oxygen concentrations in the central extraction well were still well below $1 \mathrm{ppm}$, indicating that HPO was still limited by oxygen availability.

By evaluating the carbon balance throughout the system, we are able to quantify the extent of in situ oxidation of PAHs at Visalia (Aines et al., 1998). Two nearly independent methods were employed. Isotopic analyses of Visalia effluent samples determined that a substantial amount of the extracted $\mathrm{CO}_{2}$ derived from contaminant oxidation. By balancing the depletion of "modern" carbon, we estimate that $10,100 \mathrm{~kg}$ of the extracted $\mathrm{CO}_{2}$ was generated by oxidation of organic contaminants. By evaluating the carbon sources and sinks in the Visalia, a geochemical carbon balance can be calculated based on carbonate solubility alone, indicating that $9,300 \mathrm{~kg}$ of the extracted $\mathrm{CO}_{2}$ was generated by oxidation of organic contaminants. The two estimates agree to within $8 \%$.

Using these constraints, we are able to evaluate the overall recovery achieved throughout the Visalia field during the first year of operations. As of October, 1998 , over $400,000 \mathrm{~kg}$ $(900,000 \mathrm{lb})$ of contaminant had been removed or destroyed. About $18 \%$ of the total has been destroyed in situ via HPO. Free product recovery is continuing slowly. Contaminant concentrations are dropping in the extraction wells; the site is cleaning from the periphery inward.

\section{SUMMARY}

The Visalia field tests confirmed in situ HPO destruction in soil and ground water at rates similar to those observed in the laboratory, under realistic field remediation conditions. HPO appears to work as fast as oxygen can be supplied, at rates similar to those measured in the laboratory. The predictive models used to design HPO steam injection systems have been validated by using conservative tracers to confirm mixing rates, oxygen consumption, $\mathrm{CO}_{2}$ release, and effects of real-world heterogeneity. Accurate field measurements of the critical fluid parameters (destruction chemistry, oxygen content, steam front location) were demonstrated, using existing monitoring wells and portable data systems with minimal capital cost.

The combination of physical monitoring with noble gas identification of the native and injected fluids and accurate fluid sampling resulted in an excellent temporal and spatial evaluation of the subsurface processes, from which the amount of in situ destruction occurring in the treated region could be quantified. The experimental field results constrain the destruction rates throughout the site, and enable site management to make accurate estimates of total in situ destruction based on the recovered carbon. As of October, 1998, over $400,000 \mathrm{~kg}(900,000 \mathrm{lb})$ of contaminant have been removed from the site; about $18 \%$ of this has been destroyed in situ.

\section{ACKNOWLEDGEMENTS}

We gratefully acknowledge the support of the U.S. Department of Energy's Office of Environmental Restoration and Office of Science and Technology, and LLNL's Laboratory Directed Research and Development program. This work could not have been performed without the support of the Southern California Edison Co. and its Visalia Pole Yard employees, who cheerfully worked a 24-hour schedule in support of this project. SteamTech Environmental Services of Bakersfield, California, provided field support with steaming, temperature and ERT data. We are indcbted to Allen Elsholz for his tireless operation and maintenance of all the field measuring systems and for his work with Ben Johnson and George Metzger in designing and constructing the down-hole scientific equipment. Work performed under the auspices of the U.S. Department of Energy by the Lawrence Livermore National Laboratory under Contract W-7405-Eng-48. 


\section{REFERENCES}

Aines, R.D.; Leif, F.; Knauss, K.; Newmark, R.L.; Chiarappa, M.; Davison, M.L.; Hudson, G.B., Weidner, R.; and Eaker, C.; Tracking inorganic carbon compounds to quantify in situ oxidation of polycyclic aromatic hydrocarbons during the Visalia Pole Yard hydrous pyrolysis/oxidation field test, 1998 (in prep).

Cummings, Mark A.; Visalia Steam Remediation Project: Case Study of an Integrated Approach to DNAPL Remediation. Los Alamos National Laboratory Report, LA-UR9704999; 1997; 9 pp.

Geraghty; Miller; Remedial Investigation/Feasibility Study, Southern California Edison, Visalia Pole Yard, Visalia, CA, Southern California Edison Co., 1992.

Hudson, G.B., M. L. Davisson, C. R. Carrigan, J. Nitao, R. D. Aines, R. L. Newmark and C. Eaker, Tracing and modeling of subsurface thermal treatment, First International Conference on Remediation of Chlorinated and Recalcitrant Compounds, Monterey, California, May 18-21, 1998.

Knauss, Kevin G.; Aines, Roger D.; Dibley, Michael J.; Leif, Roald N.; Mew, Daniel $A$.; Hydrous Pyrolysis/Oxidation: In-Ground Thermal Destruction of Organic Contaminants. . Lawrence Livermore National Laboratory, Report, UCRL-JC 126636, 1997; 18 pp.

Knauss, Kevin G.; Dibley, Michael J.; Leif, Roald N.; Mew, Daniel A.; Aines, Roger D. "Aqueous Oxidation of Trichloroethene (TCE): A Kinetic and Thermodynamic Analysis". In Physical, Chemical and Thermal Technologies, Remediation of Chlorinated and Recalcitrant Compunds, Proceeding of the First International Conference on Remediation of Chlorinated and Recalcitrant Compounds; Wickramanayake, G.B., Hinchee, R.E., Eds.; Battelle Press, Columbus, OH, 1998a; pp359-364. Also available as Lawrence Livermore National Laboratory, Report, UCRL-JC-129932, 1998; 8 pp.

Knauss, Kevin G.; Dibley, Michael J.; Leif, Roald N.; Mew, Daniel A.; Aines, Roger D. "Aqueous Oxidation of Trichloroethene (TCE): A Kinetic analysis." Accepted for Publication, Applied Geochemistry; $1998 \mathrm{~b}$.

Knauss, Kevin G.; Dibley, Michael J.; Leif, Roald N.; Mew, Daniel A.; Aines, Roger D. "Aqueous Oxidation of Trichloroethene (TCE) and Tetrachloroethene (PCE) as a Function of Temperature and Calculated Thermodynanmic Quantities, Submitted to Applied Geochemistry; 1998c.

Leif, Roald N.; Chiarrappa, Marina; Aines, Roger D.; Newmark Robin L:; and Knauss, Kevin G. "In Situ Hydrothermal Oxidative Destruction of DNAPLS in" a Creosote Contaminated Site." In Physical, Chemical and Thermal Technologies, Remediation of Chlorinated and Recalcitrant Compunds, Proceeding of the First International Conference on Remediation of Chlorinated and Recalcitrant Compounds; Wickramanayake, G.B., Hinchee, R.E., Eds.; Battelle Press, Columbus, OH, 1998; pp 133-138. Also available as Lawrence Livermore National Laboratory, Report, UCRL-JC-129933, 1998; 8 pp.

Leif, Roald N.; Aines, Roger D.; Knauss, Kevin G. Hydrous Pyrolysis of Pole Treating Chemicals: A) Initial Measurment of Hydrous Pyrolysis Rates for Napthalene and Pentachlorophenol; B) Solubility of Flourene at Temperatures Up To $150^{\circ} \mathrm{C}$; Lawrence Livermore National Laboratory, Report, UCRL-CR-129938, 1997a; 32pp. 
Newmark, Robin L.; Aines, Roger D.; Dumping Pump and Treat: Rapid Cleanups Using Thermal Technology. Lawrence Livermore National Laboratory, Report, UCRL-JC 126637,$1997 ; 23$ pp.

Newmark, Robin L.; Aines, Roger D, Kevin Knauss, R. Leif, M. Chiarappa, B. Hudson, C. Carrigan, A. Tompson, J. Richards, C. Eaker, R. Weidner, T. Sciarotta, In Situ Destruction of Contaminants via Hydrous Pyrolysis/Oxidation: Visalia Field Test, Lawrence Livermore National Laboratory, Report, 1998 (in prep).

Newmark, R.L., S. Boyd, W. Daily, R. Goldman, R. Hunter, D. Kayes, K. Kenneally, A. Ramirez, K. Udell, and M. Wilt, Using geophysical techniques to control in situ thermal remediation, Symposium on the Application of Geophysics to Engineering and Environmental Problems (SAGEEP) '94, Boston, Ma., March 27-31, 1994, 195-211.

Nitao, J.J., Reference Manual for the NUFT Flow and Transport Code, Version 1.0; Lawrence Livermore National Laboratoy Report, UCRL-JC-113520, 1995.

Ramirez, A.L., W. D. Daily and R. L. Newmark, Electrical resistance tomography for steam injection monitoring and process control, Journal of Environmental and Engineering Geophysics, (July, 1995), v. 0, no.1, 39-52.

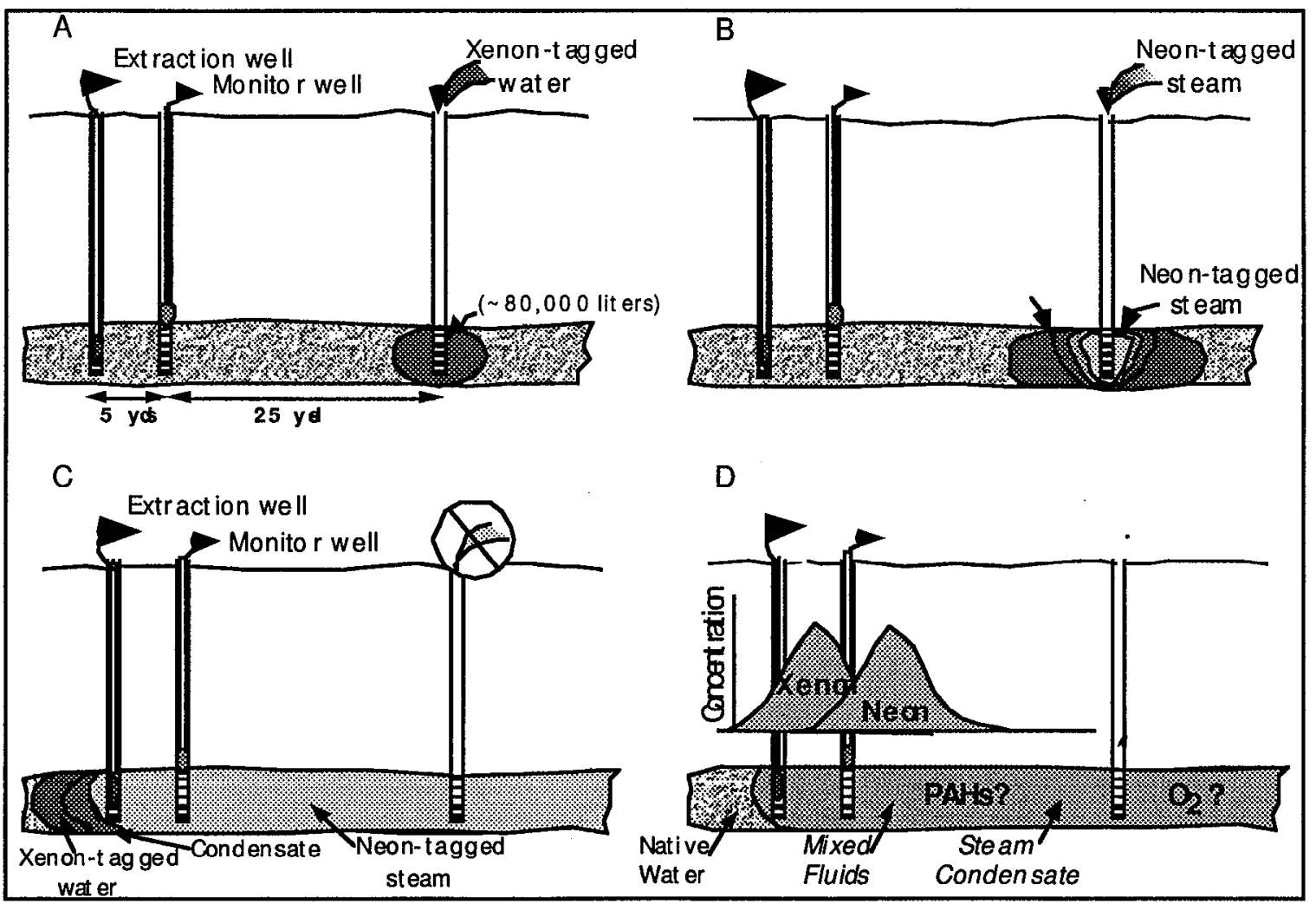

Figure 1: Conceptual design for the first tracer experiment. A) Xenon-tagged water is pumped into the injection well. B) Neon-tagged steam is injected. C) Steam passes the extraction well, injection ceases, and collapse is monitored. D) A reaction zone remains, in which heat and oxygen are available to degrade contaminants. 
First Steam Pass Temperatures

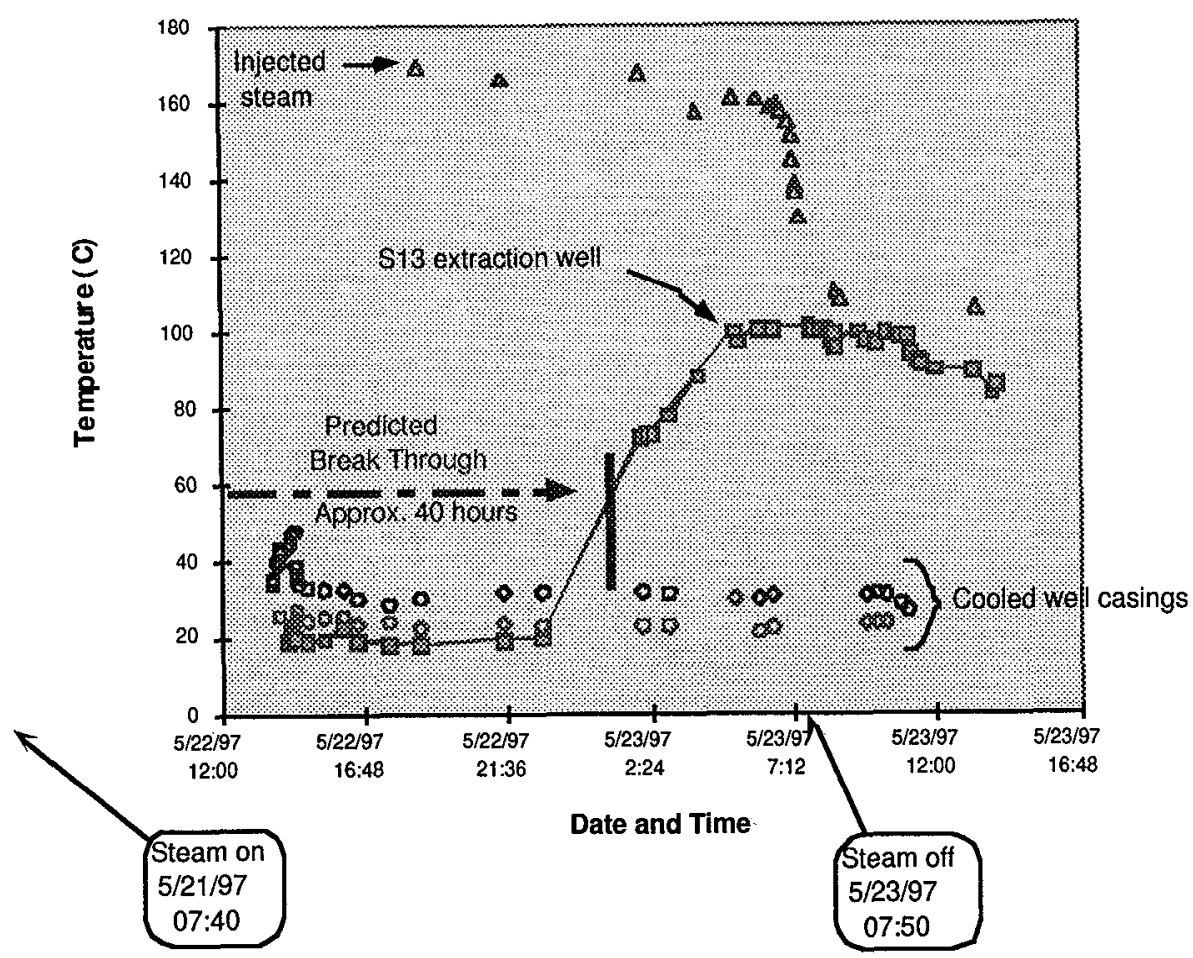

Figure 2. Temperature measurements made in the $\mathrm{S} 13$ extraction well show rapid rise on steam breakthrough, which occurred about 40 hours after injection began, as predicted by the NUFT models. Temperatures in the protected plastic monitoring well casings remained low.

A

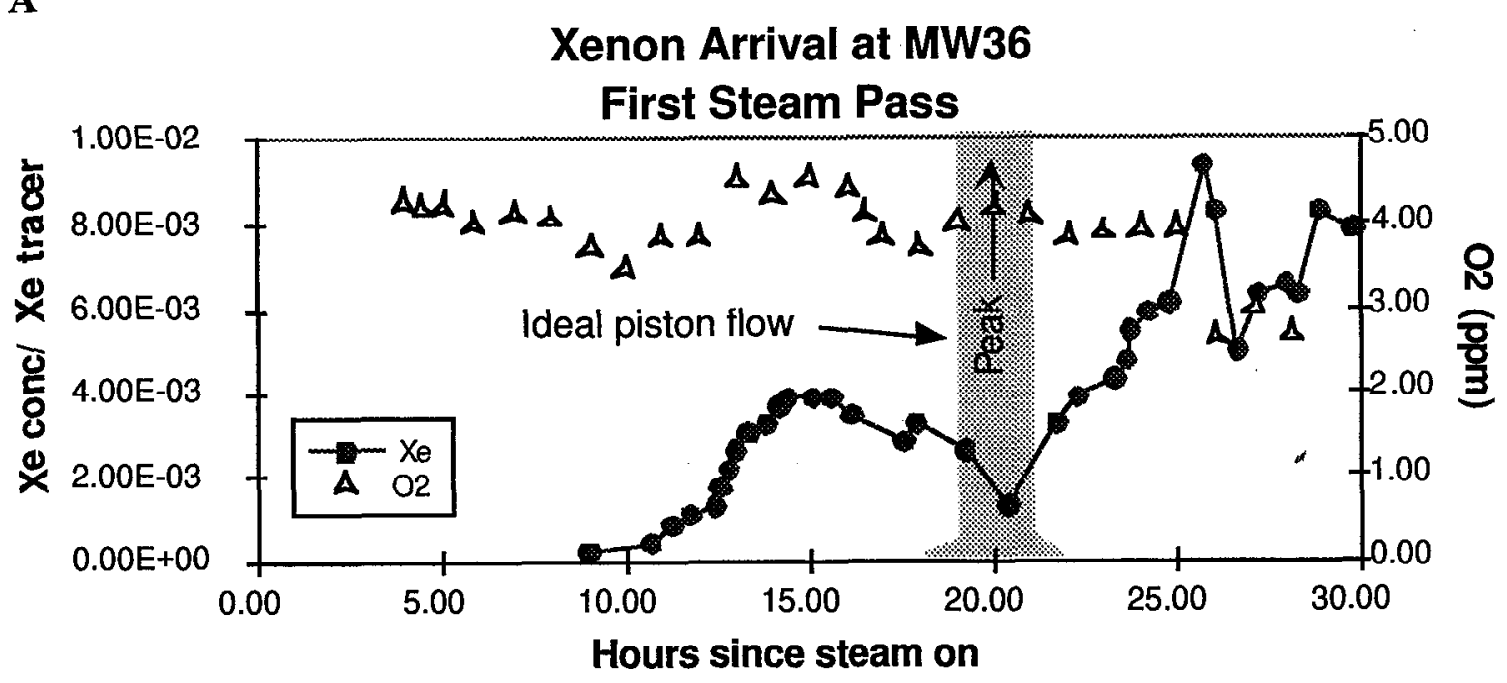


B

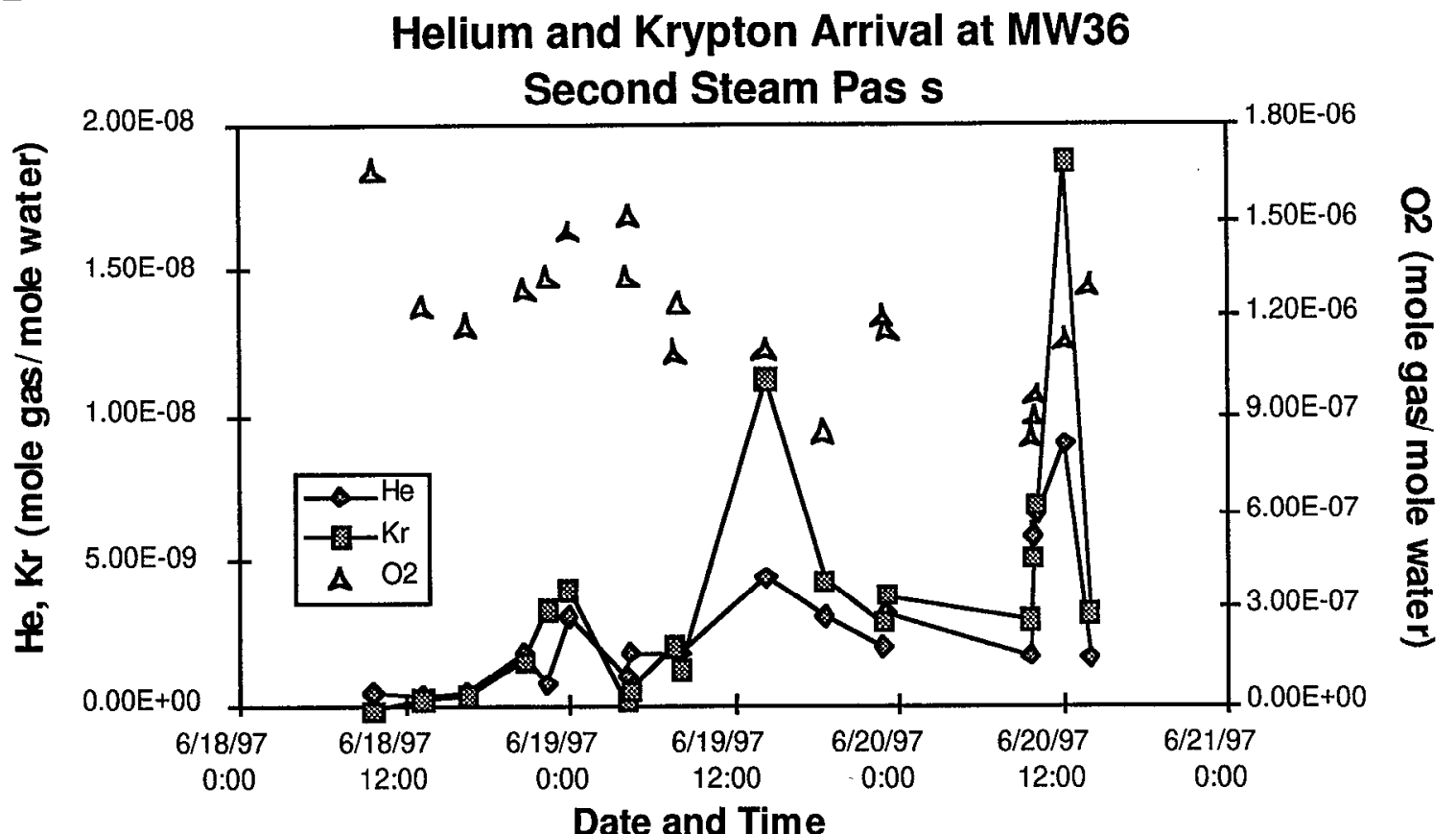

Figure 3. A) Xenon arrival at MW36 during the first tracer experiment indicates extensive mixing and dispersion within the aquifer. Xenon concentrations rose gradually over a period of approximately 30 hours. The drop in concentration from 15-20 hours resulted from a drop in injection pressure; a mini-collapse of the steam zone caused the approaching steam front to temporarily recede. Upon restored injection pressure, the steam front approached, then passed the monitoring well. If pure piston-flow displacement occurred, xenon would be expected to arrive during an approximately 2-hour window, with peak concentrations many times those observed (shaded zone). Oxygen concentration begins to dccrcase after the first 24 hours. B) Helium and krypton arrival at MW36 during the second tracer experiment. Gradual increase in concentrations support continued mixing and dispersion. Decreasing dissolved oxygen reflects the oxidation reactions consuming oxygen as it contacts contaminated fluids.

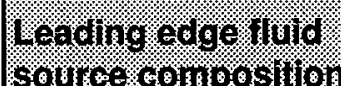

Saureescomionsition

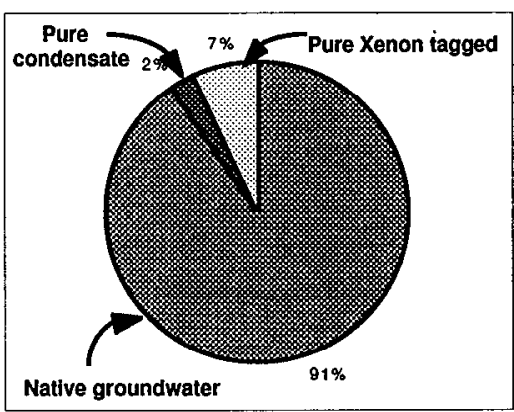

Reaction 20 ne tivitil

SSolince coinposition

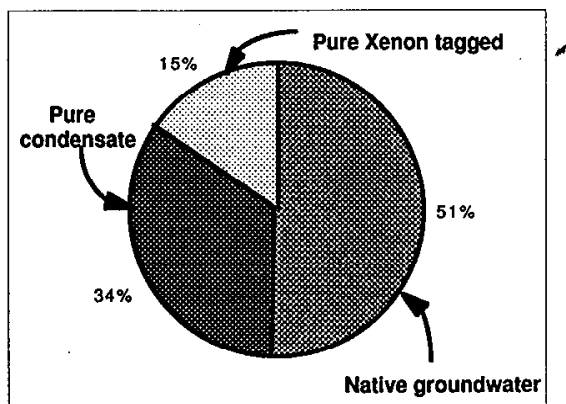

Figure 4. Tracers permit the identification of the fluid sample source composition. 